\title{
Energy and Nutritional Properties of the White Mulberry (Morus alba L.)
}

\author{
Małgorzata Łochyńska \\ Silkworms Breeding and Mulberry Cultivation Laboratory, Institute of Natural Fibres and Medicinal Plants, Wojska Polskiego $71 B$, \\ Poznań, Poland
}

\begin{abstract}
The white mulberry (Morus alba L.) had been forgotten in Europe or known only as a plant associated with breeding of mulberry silkworms (Bombyx mori L.). The initial studies have shown great potential of this plant in energy, food and pharmaceutical industries. The leaves and fruits contain very valuable bioactive substances, which may be used in health care. Antioxidants of plant origin include flavonoids and vitamin $\mathrm{C}$ (ascorbic acid), and these substances are present in high amounts in anatomical parts of white mulberry. It has also been reported on the medicinal properties of this plant and its use in preventing diseases, such as atherosclerosis, diabetes, obesity and cancer. The food industry increasingly uses the white mulberry in food to provide human organism with precious bioactive substances. Functional food, due to the presence in its composition of valuable components, is beneficial to human health. What is more, very fast growth of mulberry causes that biomass of the plant may be used as biofuel or energy plant. The aim of this paper is to present the possibility of using the white mulberry as a raw material for functional foods and as an energy plant.
\end{abstract}

Key words: Energy plant, antioxidants, functional food, diseases of civilization.

\section{Introduction}

Morus alba Linnaeus, 1753 is one of numerous species in the Moraceae link family. Most of the mulberries are native to Asian regions with warm climate. These plants are characterized with milky sap in shoots. They are both monoecious and dioecious, their flowers are inconspicuous and odorless, and the small, multiple sweet fruits occur in the form of drupelets or nuts. The leaves are alternately arranged, simple, often lobed and serrated on the margin.

Nowadays, the white mulberry is almost forgotten in Europe or known only as a food plant of mulberry silkworm (Bombyx mori L.). Nevertheless, potential of this plant is really huge. Very fast growth of mulberry causes that the plant biomass may be used as biofuel. In India, all annual shoots, available after silkworm breeding season, are cut, dried and used as the main renewable source of fuel [1]. What is more, white

Corresponding author: Małgorzata Łochyńska, Ph.D., research fields: botany and sericulture. mulberry is also used as a natural dyeing plant [2], in the sport equipment industry and furniture industry [3], and the branches are used as a substrate for oyster mushrooms (Pleurotus sp.) [4]. But, the most important feature of the white mulberry is its high value in terms of healthfulness. Almost all parts of the mulberry are used in the food industry. Fruits are eaten directly and processed into wines, jams, juices; they are also added to cakes. Leaves are used as teas, infusions and as a salad ingredient. Moreover, roots are boiled and added to soups and casseroles. The literature also reports that the seeds were used in oil production [5].

Free radicals, formed during metabolic processes, are responsible for occurrence of numerous diseases. For neutralizing free radicals, and what follows, for preventing the diseases of lifestyle, natural antioxidants play an important role. Cardiovascular and respiratory system diseases, atherosclerosis, anemia, obesity, diabetes and cancer, the so called diseases of civilization, have become commonplace in 
the modern society. The causes of these diseases can be linked with rapid civilization progress, which brings about heavy pollution of natural environment, noise, stress and unhealthful dietary habits. Another, equally important factor is the commonplace occurrence of free radicals, which are present in industrial processes, atmospheric phenomena and in basic physiological processes.

Well balanced and proper diet allows human organism for good functioning, and good selection of the dietary components can also prevent the onset of diseases and alleviate their symptoms, which properties are characteristic for functional food. White mulberry, due to its healthy properties, should be used for functional food to a much greater extent than it is done nowadays. This could improve the quality of life of numerous groups of people.

The aim of this paper is to present the white mulberry properties, which are important for agriculture and human health, and discuss its utilisation in energy industry, functional food, food industry and civilization diseases prevention.

\section{Energy Biomass}

The mulberry shows great potential in fuel and energy production. In India, all annual shoots, available after silkworm breeding season, are cut, dried and used as the main renewable source of fuel [1]. There is no doubt that fast-growing mulberry, rich in cellulose (57.4\%), hemicellulose (16.3\%) and lignin (24.6\%) possess huge energy value $14-17.9 \mathrm{MJ} / \mathrm{kg}$ [2, 6]. In addition, the mulberry shows a resistance to disease and pests, and has relatively low soil requirements. Mulberry plantations provide a low utilization of productive or degraded agricultural land. Therefore, it may be used to produce heat, electricity and liquid and gas fuel production (bulk, pellets, briquettes, slurry in anaerobic digesters). All these properties of the white mulberry show that it may be much better than energy willow Salix viminalis, rape straw, mallow Sida hermaphrodita and kenaf Hibiscus cannabinus [7-10].

\section{Chemical Composition}

Mulberry fruits, leaves and roots contain high amounts of bioactive substances, thus this plant has been traditionally used in medicine for ages [11]. Previous studies have shown that leaves and dark fruits are the richest in bioactive compounds [12-14]. It is reported that leaves contain on dry weight $15.31 \%-30.91 \%$ of high quality proteins, $2.09 \%-7.92 \%$ fat, $9.9 \%-13.85 \%$ crude fiber, $27.6 \%-43.6 \%$ neutral dietary fiber and $11.3 \%-17.24 \%$ ash contents [15]. Moreover, chemical investigation of leaves showed occurrence of ascorbic acid (100-200 $\mathrm{mg} / 100 \mathrm{~g})$, beta-carotene $(8.44-13.13 \mathrm{mg} / 100 \mathrm{~g})$, oxalates $(183 \mathrm{mg} / 100 \mathrm{~g})$, phytates $(156 \mathrm{mg} / 100 \mathrm{~g})$, tannic acid $0.13 \%-0.36 \%$ and minerals iron (19-50 $\mathrm{mg} / 100 \mathrm{~g})$, zinc $(0.72-3.65 \mathrm{mg} / 100 \mathrm{~g})$, calcium (786.66-2,726.66 mg/100 g), phosphorus (970 mg/100 g) and magnesium $(720 \mathrm{mg} / 100 \mathrm{~g})$ [15].

Mulberry leaves are a rich source of 14 polyphenolic substances. Leaf extracts contain considerable quantity of flavonoids, i.e., quercetin 3-(6-malonyl glucoside), rutin, kaempferol 3-(6-malonyl glucoside), astragalin and phenol acids of chlorogenic and caffeic. In the total content of antioxidants, chlorogenic acid and quercetin constitute the major part [16]. The total content of phenols ranges from $12.81 \mathrm{mg}$ gallic acid equivalents (GAE)/g dry weight (dw) to $15.50 \mathrm{mg} \mathrm{GAE} / \mathrm{g} \mathrm{dw}$. The total content of four caffeoylquinic acids (CQAs) for Morus alba ranges from $6.78 \mathrm{mg} / \mathrm{g}$ dw to $8.48 \mathrm{mg} / \mathrm{g} \mathrm{dw}$ and total 10 flavonols range from $3.66 \mathrm{mg} / \mathrm{g}$ dw to 9.75 $\mathrm{mg} / \mathrm{g} \quad \mathrm{dw}$ [12]. Moreover, leaves contain 18 polyhydroxylated alkaloids, including the most popular 1-deoxynojirimycin (DNJ), which ranges from 0.28 $\mathrm{mg} / \mathrm{g}$ to $3.88 \mathrm{mg} / \mathrm{g}[17,18]$. What is more, mulberry leaves possess very high antioxidant capacity. Two assays 2, 2'-azinobis (3-ethylbenzthiazoline-6-acid) (ABTS) and (2, 2-diphenyl-1-picrylhydrazyl) (DPPH) were used to evaluate antioxidant activity, and the means values from 10.6 Trolox $/ \mathrm{g} d \mathrm{~d}$ to $13.15 \mathrm{mg}$ 
Trolox/g dw for ABTS and from 10.62 Trolox $/ g$ dw to $12.64 \mathrm{mg}$ Trolox/g dw for DPPH were presented [12].

Phytochemical investigations have indicated also polysaccharides in the white mulberry leaves. The content of soluble carbohydrate was detected from $81.18 \%$ to $83.42 \%[15,19,20]$. The detailed information about carbohydrate composition showed that total soluble carbohydrates was $3.1 \mathrm{~g} / 100 \mathrm{~g}$ fresh weight (fw), reducing sugars of $1.5 \mathrm{~g} / 100 \mathrm{~g} \mathrm{fw}$, monosaccharides fructose and glucose of $0.3 \mathrm{~g} / 100 \mathrm{~g}$ $\mathrm{fw}$ and sucrose of $1.1 \mathrm{~g} / 100 \mathrm{~g} \mathrm{fw}$ [21]. Moreover, mulberry leaves extracts provide strong antibacterial potential due to the presence of albanol B, kuwanon $\mathrm{C}$ and $\mathrm{G}$, halkomoracin, morusin, mulberrofuran $\mathrm{G}$, sangennon $\mathrm{B}$ and $\mathrm{D}[15,22]$.

The mulberry fruits are also of significant importance in human nutrition. The content of fruits protein was $1.55 \mathrm{~g} / 100 \mathrm{~g} \mathrm{dw}$, lipid content of 0.48 $\mathrm{g} / 100 \mathrm{~g} \mathrm{dw}$, the crude fibre of $1.47 \mathrm{~g} / 100 \mathrm{~g} \mathrm{dw}$, ash content of $0.57 \mathrm{~g} / 100 \mathrm{mg} \mathrm{dw}$, total carbohydrates content of $14.21 \mathrm{~g} / 100 \mathrm{~g} \mathrm{dw}$ and moisture of fresh weight was $81.72 \mathrm{~g} / 100 \mathrm{~g} \mathrm{dw}$ [23]. The sugars content (total $7.55 \mathrm{~g} / 100 \mathrm{~g}$ fw), vitamin $\mathrm{B}_{2}$ (riboflavin, 0.088 $\mathrm{mg} / 100 \mathrm{~g} \mathrm{fw})$, niacin $(3.10 \mathrm{mg} / 100 \mathrm{~g} \mathrm{fw})$, ascorbic acid $(15.2 \mathrm{mg} / 100 \mathrm{~g} \mathrm{fw})$ were also detected [23]. The detailed information about carbohydrate composition in fruits showed that total soluble carbohydrates was $3.4 \mathrm{~g} / 100 \mathrm{~g} \mathrm{fw}$, reducing sugars $1.7 \mathrm{~g} / 100 \mathrm{~g} \mathrm{fw}$, monosaccharides fructose $3.0 \mathrm{~g} / 100 \mathrm{~g}$ fw, glucose 3.1 $\mathrm{g} / 100 \mathrm{~g} \mathrm{fw}$, fructooligosaccharides 1-ketose $0.1 \mathrm{~g} / 100$ $\mathrm{g}$ fw, nystose $0.01 \mathrm{~g} / 100 \mathrm{~g}$ fw and inulin $0.04 \mathrm{~g} / 100 \mathrm{~g}$ fw $[21,24]$. What is more, mulberry fruits are rich in minerals. The content of macro-elements on dry weight basis is: $\mathrm{N}(1.62-2.13 \mathrm{~g} / 100 \mathrm{~g}), \mathrm{P}(0.24-0.31$ $\mathrm{g} / 100 \mathrm{~g}), \mathrm{K}(1.62-2.13 \mathrm{~g} / 100 \mathrm{~g}), \mathrm{Ca}(0.19-0.37 \mathrm{~g} / 100$ g), Na $(0.01 \mathrm{~g} / 100 \mathrm{~g}), \mathrm{Mg}(0.12-0.19 \mathrm{~g} / 100 \mathrm{~g}), \mathrm{S}$ $(0.08-0.11 \mathrm{~g} / 100 \mathrm{~g})$; and micro-elements is: $\mathrm{Fe}$ $(28.2-46.74 \mathrm{mg} / \mathrm{kg}), \quad \mathrm{Cu} \quad(4.22-6.38 \mathrm{mg} / \mathrm{kg}), \quad$ B (13.78-19.48 mg/100 g), Mn (12.33-19.38 mg/kg), Zn $(14.89-19.58 \mathrm{mg} / \mathrm{kg})$ and $\mathrm{Ni}(1.40-2,62 \mathrm{mg} / \mathrm{kg})$ [13]. Moreover, mulberry fruits are rich in phenolic compounds, including flavonols and phenolic acids, as well as anthocyanins, particularly in the case of dark fruits [13]. The total phenolic contain in fruits ranged from 7.7 to $11.2 \mathrm{mg} \mathrm{GAE} / \mathrm{g} \mathrm{dw}$, and flavonols from 0.07 to $0.51 \mathrm{mg} / \mathrm{g} \mathrm{dw}$ [13]. Moreover, the high amount of alkaloids $(660 \mathrm{mg} / 100 \mathrm{~g})$ was found in fresh fruits [23]. The antioxidant capacity of dark fruits is significant, while mean values ranged from $3.84 \mathrm{mg}$ Trolox/g dw to $20.73 \mathrm{mg}$ Trolox $/ \mathrm{g}$ dw for ABTS and from $3.62 \mathrm{mg}$ Trolox/g dw to $12.91 \mathrm{mg}$ Trolox $/ \mathrm{g} \mathrm{dw}$ for DPPH [13].

The mulberry seeds contain $25 \%-35 \%$ of yellow oil rich in precious fatty acids group omega-3 [3]. The fatty acids examination shows that within 13 recorded acids, seven are mono- and poly-unsaturated fatty acids (MUFAs and PUFAs), which belong to very precious fatty acids group omega-3. Linoleic acid (LA, C18:2n6c; 76.84\%) and oleic acid (C18:1n9c; 7.09\%) show the highest content. Trace amounts of other unsaturated fatty acids, such as linolenic, stearidonic, eicosadienoic, eicosanoic and erucic acid, were also recorded [3, 15].

Moreover, root bark of the white mulberry contains flavonoids, alkaloids and stilbenoids and leachianone G against herpes simplex type 1 virus (HSV-1) [15].

\section{Health Care Properties}

Human organism is equipped with a protective mechanism against free radicals, which system comprises endogenic antioxidants. However, exogenic antioxidants play an important role in reducing the oxidative damage. The white mulberry is very rich source of antioxidants, including ascorbic acid (vitamin C), anthocyanins and polyphenols. These active substances are crucial in protecting and preventing human organism against civilization diseases, such as atherosclerosis, diabetes, obesity and cancer [24].

Traditional Chinese medicine still uses leaves and fruits of mulberry in treating fever, eye diseases, for rinsing throat in inflammations of upper respiratory 
system, as sudorific and anti-parasitic preparations, in strengthening of joints, and lowering high blood pressure and high cholesterol levels. Root extracts are used as anti-inflammatory medicines, painkillers and preparations for protecting liver and kidneys [25]. In addition, the mulberry seeds contain $25 \%-35 \%$ of a yellow oil, white mulberry may be used as an oil-bearing plant. Detected unsaturated fatty acids are essential unsaturated fatty acids (EUFA), so called vitamin $\mathrm{F}$, which can not be produced in human organism and must be supplied with food. They prevent arteriosclerosis, thrombosis and embolism, so that they are used in prevention of heart disease [3].

However, the white mulberry is mainly known for its excellent antidiabetic action. The flavonoids contained in the leaves and bark of mulberry, especially quercetin and DNJ, significantly lower blood glucose levels by inhibiting enzyme activity, such as $\alpha$-glucosidases, sucrase and maltase [26]. It was shown that ethanol extracts of mulberry leaves can prevent obesity [27]. What is more, the components of mulberry extracts also significantly inhibit the atherosclerotic by low-density lipoprotein (LDL) oxidation and increasing resistance to blood cholesterol deposits $[15,28,29]$. In addition, the extract from the mulberry bark achieves good results in relieving the state of atherosclerosis, oxidation, aggregation and retention of LDL [25]. The white mulberry contains also high amounts of $\beta$-carotene, curcumin, gingerol, galusan epigallocatechins and resveratrol, which are considered as components of antioxidants important in cancer prevention [15]. The mulberry flavonoids (rutin, isoquercitrin, astragalin, quercetin) and anthocyanins - the most important antioxidants, show cytotoxic activity against liver cancer cells in rats, human leukemia and melanoma cells in mice [30-32]. The polysaccharides from the roots bark stimulate lymphocyte proliferation and reduce the production of antibodies, which plays a significant role in treatment against allergies and is used in allergic diseases [33]. Moreover, the cyanidin from fruits protects human brain against endothelial dysfunction and reduces the likelihood of Alzheimer's disease [34]. The literature data also reported considerable capacity of mulberry for local whitening of skin (depigmentation). The extract of mulberry causes strong inhibition of dihydroxyphenylalanine (DOPA) oxidase and exhibits activity against tyrosinase, which inhibits the overproduction of melanin and causes its degradation in local hyperpigmentations, e.g., melanoma, ephelide, lentigo $[35,36]$. Bioactive compounds extracted from mulberry exhibit also strong antiviral and antibacterial activity [37]. Leaves extracts provide antimicrobial potential against Bacillus subtilis, Staphylococcus aureus, Escherichia coli, Streptococcus faecalis, Streptococcus mutans, Mycobacterium smegmatis, and root bark with leachianone G against HSV-1 [15].

\section{The White Mulberry in Food Industry}

The properties of leaves and fruits of the white mulberry are used more and more commonly for production of food of beneficial effect on human health. Moreover, nutritional effects of mulberry, improvement of health state and well-being and/or reduction of risk of disease are also used in functional foods production. Apart from that, there are more terms for dietary products containing extracts or dried mulberry.

These days, innovative health care food with mulberry extract is prepared for improving human immunity and health [13, 15, 38]. Chocolade represents functional properties due to its high level of flavonoid content. Polyphenol-rich chocolade, probiotic and prebiotic chocolade or chocolade with mulberry extract or anthocyanins were studied and produced [39].

These days, dried and powdered mulberry leaves or its extracts are used in many ways. Tea infusion does not contain caffeine and is characterized with mild and pleasant flavour. Infusion of leaves shows very good properties when used during flu, cold and throat 
inflammations. Dried material is also used in Indian cooking for baking bread from wheat flour called "paratha" and in Thailand for rice snacks with added powdered leaves of white mulberry. In addition, the white mulberry fruits are added to muesli and it is able not only to increase the antioxidant capacity of product, but also to reduce the advanced oxidative changes of the product [40]. New functional yogurts using jam and leaves of mulberry were also analyzed [41]. What is obvious, the mulberry fruits usage is also for preparing jams, ice-creams, vinegars, juices, wine and cosmetic products [42]. In comparison with grape wine, mulberry wine has higher antioxidant potential and better phenolic profile [43].

The white mulberry fruits contain $20 \%$ sugars, mainly glucose, maltose, sucrose and fructose [44]. They also contain organic acids: citric and cider acids and volatile oils. Due to such high content of easily digestible sugars, populations of high mountain regions dry mulberry fruits then were grinded to flour and added to various dishes.

The dietary fiber refers to different carbohydrates and lignin that resist hydrolysis by human digestive enzymes, but can be fermented by colonic microflora. This definition includes polysaccharides (cellulose, hemicellulose, pectins, gums, betaglucans), inulin, fructooligosaccharides (FOS), galactooligosaccharides (GOS), resistant starch. Some of these fiber components satisfy strictly criteria to be considered as prebiotics (inulin, FOS, GOS, soy oligosaccharides) [45].

According to the inulin content, Morus alba has very beneficial activities for colonic microflora Bifidobacterium and Lactobacillus [46]. One of the ways of increasing the number of beneficial intestinal microorganisms is the use of prebiotic ingredients, and to be able to generate the bifidogenic effect is necessary for the counting of cultures prebiotics in the colon [47]. The oligosaccharides associated with intestinal bacteria guide the $\mathrm{T}$ lymphocytes maturation, closely linked to the prevention of gastrointestinal diseases [24].

Moreover, dried mulberry fruits are used as a source of regenerative and strengthening food [48, 49]. The root bark of mulberry contains flavonoids, alkaloids and stilbenoids. It has antimicrobial, skin-whitening, cytotoxic, anti-inflammatory and anti-hyperlipidemic activity [50].

\section{Conclusions}

High energy value of mulberry shoots, their very fast growth and high content of cellulose, hemicellulose and lignins, a resistance to disease and pests and relatively low soil requirements cause that the white mulberry is really good new source of green energy. Leaves collected from mulberry plantations may be used in sericulture, pharmaceutical industry, in medicine and food industry, and shoots in energy industry as bulk, pellets, briquettes, slurry in anaerobic digesters. All these properties of white mulberry show that this plant may be used multi-directionally. That is why it is much better than energy willow Salix viminalis and other energy plants.

Numerous studies indicate significance of the antioxidative properties of the white mulberry in preventing and treating lifestyles diseases. Its beneficial effect is observed for extracts obtained from various parts of the plant. Thus, constant and systematic supplementation in antioxidants to balance their levels in the organism seems advisable. It is believed that functional food is the best way to introduce exogenic antioxidants to human organism. A functional food is a natural food, which components have been added or removed by technological or biotechnological means. Therefore, functional food is the safest for human health and does not interfere with other treatments.

Although the healthful properties of mulberry have been well documented, further research is needed on the characterization of bioactive components of 
mulberry. Promoting diets rich in natural sources of antioxidants should be the main aim of health policy.

\section{References}

[1] Chinnaswamy, K. P., and Hariprasad, K. B. 1995. "Fuel Energy Potentiality of Mulberry." Indian Silk 34 (4): 15-8.

[2] Sharma, S., and Madan, M. 1994. "Potential of Mulberry (Morus alba) Biomass." Journal of Scientific and Industrial Research 53 (9): 710-4.

[3] Łochyńska, M., and Oleszak, G. 2011. "Multipurpose White Mulberry (Morus alba L.)." In Renewable Resources and Biotechnology for Material Applications, edited by Zaikov, G. E., Pudel, D. P., and Spychalski, G. New York: Nova Publishers, 59-65.

[4] Madan, M., Sharma, S., and Vasudevan, P. 1992. "Mineral Content of Pleurotus sajor-caju and Organic Substrates Used." Microbios 69 (279): 113-8.

[5] Sývacý, A., and Semen, M. 2004. "Seasonal Changes in Antioxidant Activity, Total Phenolic and Anthocyanin Constituent in the Stems of Two Morus Species (Morus alba L. and Morus nigra L.)." Plant Growth Regulation 44 (3): 251-6.

[6] Łochyńska, M., and Oleszak, G. 2011. "Multi-use of the White Mulberry (Morus alba L.)." Ecological Questions 15: 91-5.

[7] Stolarski, M., Szczukowski, S., and Tworkowski, J. 2002. "Productivity Clones and Shrubby Willows Grown on Arable Land Depending on the Frequency of Harvesting and Planting Density." Fragmenta Agronomia 2: 41-8. (in Polish)

[8] Niedziółka, I., and Zuchniarz, A. 2006. "Analysis of Selected Types of Biomass Energy Plant.” Motorol. 8: 232-7. (in Polish)

[9] Kołodziej, J., Mańkowski, J., and Kubacki, A. 2007. "Energetic Properties of the Waste Processing of Flax and Hemp in Comparison with Other Plant Materials." Newsletter of the Polish Chamber of Flax and Hemp 8: 35-43. (in Polish)

[10] Burczyk, H., and Kolodziej, J. 2009. "Comparison of Yield and Energy Value of Hemp, Maize and Sorghum with Exotic Plants." Newsletter of the Polish Chamber of Flax and Hemp 12: 22-36. (in Polish)

[11] Srivastava, S., Kapoor, R., Thathola, A., and Srivastava, R. P. 2003. "Mulberry (Morus alba) Leaves as Human Food: A New Dimension of Sericulture." International Journal of Food Sciences and Nutrition 54 (6): 411-6.

[12] Sánchez-Salcedo, E. M., Mena, P., García-Viguera, C., Hernández, F., and Martínez, J. J. 2015. "(Poly)phenolic Compounds and Antioxidant Activity of White (Morus alba L.) and Black (Morus nigra L.) Mulberry Leaves:
Their Potential for New Products Rich in Phytochemicals." Journal of Functional Foods 18: 1039-46.

[13] Sánchez-Salcedo, E. M., Mena, P., García-Viguera, C., Martínez, J. J., and Hernández, F. 2015. "Phytochemical Evaluation of White (Morus alba L.) and Black (Morus nigra L.) Mulberry Fruits: A Starting Point for the Assessment of Their Beneficial Properties." Journal of Functional Foods 12: 399-408.

[14] Jiang, Y., and Nie, W. J. 2015. "Chemical Properties in Fruits of Mulberry Species from the Xinjiang Province of China." Food Chemistry 174: 460-6.

[15] Butt, M. S., Nazir, A., Sultan, M. T., and Schoën, K. 2008. "Morus alba L. Nature's Functional Tonic." Trends in Food Science and Technology 19 (10): 505-12.

[16] Katsube, T., Tsurunaga, Y., Sugiyama, M., Furuno, T., and Yamasaki, Y. 2009. "Effect of Air-Drying Temperature on Antioxidant Capacity and Stability of Polyphenolic Compounds in Mulberry (Morus alba L.) Leaves." Food Chemistry 113 (4): 964-9.

[17] Asano, N., Yamashita, T., Yasuda, K., Ikeda, K., Kameda, Y., Kato, A., Nash, R. J., Lee, H. S., and Ryu, K. S. 2001. "Polyhydroxylated Alkaloids Isolated from Mulberry Trees (Morus alba L.) and Silkworms (Bombyx mori L.)." Journal of Agricultural and Food Chemistry 49 (9): 4208-13.

[18] Ji, T., Li, J., Su, S. L., Zhu, Z. H., Guo, S., Qian, D. W., and Duan, J. A. 2016. "Identification and Determination of the Polyhydroxylated Alkaloids Compounds with $\alpha$-Glucosidase Inhibitor Activity in Mulberry Leaves of Different Origins." Molecules 21 (2): 206.

[19] Chen, C., You, L. J., Abbasi, A. M., Fu, X., and Liu, R. H. 2015. "Optimization for Ultrasound Extraction of Polysaccharides from Mulbery Fruits with Antioxidant and Hyperglycemic Activity in Vitro." Carbohydrate Polymers 130: 122-32.

[20] Zhang, D. Y., Wan, Y., Xu, J. Y., Wu, G. H., Li, L., and Yao, X. H. 2016. "Ultrasound Extraction of Polysaccharides from Mulberry Leaves and Their Effect on Enhancing Antioxidant Activity." Carbohydrate Polymers 137: 473-9.

[21] Dimitrova, M. P., Petkova, N. T., Denev, P. P., and Aleksieva, I. N. 2015. "Carbohydrate Composition and Antioxidant Activity of Certain Morus Species." International Journal of Pharmacognosy and Phytochemical Research 7 (3): 621-7.

[22] Kostić, D. A., Dimitrijević, D. S., Mitić, S. S., Mitić, M. N., Stojanović, G. S., and Zivanović, A. V. 2013. "A Survey on Macro- and Micro-elements, Phenolic Compounds, Biological Activity and Use of Morus spp. (Moraceae)." Fruits 68 (4): 333-47.

[23] Imran, M., Khan, H., Shah, M., Khan, R., and Khan, F. 
2010. "Chemical Composition and Antioxidant Activity of Certain Morus Species." Journal of Zhejiang University Science B-Biomedicine \& Biotechnology 11 (12): 973-80.

[24] Rolim, P. M. 2015. "Development of Prebiotic Food Products and Health Benefits." Food Science and Technology 35 (1): 3-10.

[25] Katsube, T., Imawaka, N., Kawano, Y., Yamazaki, Y., Shiwaku, K., and Yamane, Y. 2006. "Antioxidant Flavanol Glycosides in Mulberry (Morus alba L.) Leaves Isolated Based on LDL Antioxidant Activity." Food Chemistry 97 (1): 25-31.

[26] Oku, T., Hamada, M., Nakamura, M., Sadamori, N., and Nakamura, S. 2006. "Inhibitory Effects of Extractives from Leaves of Morus alba on Human and Rat Small Intestinal Disaccharidase Activity." British Journal of Nutrition 95 (5): 933-8.

[27] Naowaboot, J., Pannangpetch, P., Kukongviriyapan, V., Kongyingyoes, B., and Kukongviriyapan, U. 2009. "Antihyperglycemic, Antioxidant and Antiglycation Activities of Mulberry Leaf Extract in Streptozotocin-Induced Chronic Diabetic Rats." Plant Foods for Human Nutrition 64 (2): 116-21.

[28] Chen, P. N., Chu, S. C., Chiou, H. L., Kuo, W. H., Chiang, C. L., and Hsieh, Y. S. 2006. "Mulberry Anthocyanins Cyanidin 3-Rutinoside and Cyaniding 3-Glucoside Exhibited an Inhibitory Effect on the Migration and Invasion of a Human Lung Cancer Cell Line.” Cancer Letter 235 (2): 248-59.

[29] Sharma, S. B., Tanwar, R. S., Rini, A. C., Singh, U. R., Gupta, S., and Shukla, S. K. 2010. "Protective Effect of Morus rubra L. Leaf Extract on Diet-Induced Atherosclerosis in Diabetic Rats." Indian J. Biochem. Biophys. 47 (1): 26-31.

[30] Doi, K., Kojami, T., Makino, M., Kiura, Y., and Fujimoto, Y. 2001. "Studies on the Constituents of the Leaves of Morus alba L.." Chemical and Pharmacology Bulletin 49 (2): 151-3.

[31] Kofujita, H., Yaguchi, M., Doi, N., and Suzuki, K. 2004. "A Novel Cytotoxic Prenylated Flavonoid from the Root of Morus alba." Journal of Insect Biotechnology and Sericology 73 (3): 113-6.

[32] Iqbal, S., Younas, U., Sirajuddin, Chan, K. W., Sarfraz, R. A., and Uddin, K. 2012. "Proximate Composition and Antioxidant Potential of Leaves from Three Varieties of Mulberry (Morus sp.): A Comparative Study.” Int. J. Mol. Sci. 13 (6): 6651-64.

[33] Kim, H. M., Han, S. B., Lee, K. H., Lee, C. W., Kim, C. Y., Lee, E. J., and Huh, H. 2000. "Immunomodulating Activity of a Polysaccharide Isolated from Mori Cortex Radicis." Archives of Pharmacological Research 23 (3): 240-2.
[34] Serraino, I., Dugo, L., Dugo, P., Mondello, L., Mazzon, E., Dugo, G., Caputi, A. P., and Cuzzocrea, S. 2003. "Protective Effects of Cyanidin-3-Oglucoside from Blackberry Extract against Peroxynitrite-Induced Endothelial Dysfunction and Vascular Failure." Life Science 73 (9): 1097-114.

[35] Iozumi, K., Hoganson, G. E., Pennella, R., Everett, M. A., and Fuller, B. B. 1993. "Role of Tyrosinase as the Determinant of Pigmentation in Cultures Human Melanocytes." Journal of Investigative Dermatology 100 (6): 806-11.

[36] Fang, S. H., Hou, Y. C., and Chao, P. D. 2005. "Pharmacokinetic and Pharmacodynamic Interactions of Morin and Cyclosporine." Toxicology and Applied Pharmacology 205 (1): 65-70.

[37] Du, J., He, Z. D., Jiang, R. W., Ye, W. C., Xu, H. X., and But, P. P. H. 2003. "Antiviral Flavonoids from the Root Bark of Morus alba L.." Phytochemistry 62 (8): 1235-8.

[38] Lin, J. Y., and Tang, C. Y. 2007. "Determination of Total Phenolic and Flavonoid Contents in Selected Fruits and Vegetables, as Well as Their Stimulatory Effects on Mouse Splenocyte Proliferation." Food Chemistry 101 (1): 140-7.

[39] Gültekin-Özgüven, M., Karadağ, A., Duman, Ş., Özkal, B., and Özçelik, B. 2016. "Fortification of Dark Chocolate with Spray Dried Black Mulberry (Morus nigra) Waste Extract Encapsulated in Chitosan-Coated Liposomes and Bioaccessability Studies." Food Chemistry 201: 205-12.

[40] Kobus-Cisowska, J., Gramza-Michałowska, A., Kmiecik, D., Flaczyk, E., and Korczak, J. 2013. "Mulberry Fruits as an Antioxidant Component in Muesli." Agricultural Sciences 4: 130-5.

[41] Lee, A. C., and Hong, Y. H. 2010. "Development of Functional Yogurts Prepared with Mulberries and Mulberry Tree Leaves." Korean Journal for Food Science of Animal Resources 30 (4): 649-54.

[42] Natić, M. M., Dabić, D. C., Papetti, A., Akśić, M. M. F., Ognjanov, V., Ljubojević, M., and Teśić, Z. 2015. "Analysis and Characterization in Mulberry (Morus alba L.) Fruits Grown in Vojvodina, North Serbia." Food Chemistry 171: 128-36.

[43] Celep, E., Charehsaz, M., Akyuz, S., Acar, E. T., and Yesilada, E. 2015. "Effect of in Vitro Gastrointestinal Digestion on the Bioavailability of Phenolic Components and the Antioxidant Potentials Some Turkish Fruit Wines." Food Research International 78: 209-15.

[44] Ercisli, S., and Orhan, E. 2007. "Chemical Composition of White (Morus alba), Red (Morus rubra) and Black (Morus nigra) Mulberry Fruits." Food Chemistry 103 (4): 1380-4. 
[45] World Health Organization (WHO). 2004. Diet, Nutrition and Prevention of Chronic Diseases. Report of a Joint WHO/FAO Expert Consultation, WHO Technical Report Series No. 916, Geneva WHO.

[46] Cummings, J. H., and Macfarlane, G. T. 2002. "Gastrointestial Effects of Prebiotics." The British Journal of Nutrition 87: 145-51.

[47] Gibson, G. R., and Fuller, R. 2000. "Aspects of in Vitro and in Vivo Research Approaches Directed toward Identifying Probiotics and Prebiotics for Human Use." The Journal of Nutrition 130: 391-5.

[48] Jeszka, M., Kobus-Cisowska, J., and Flaczyk, E. 2009.
"Mulberry Leaves as a Source of Natural Substances Biologically Active." Progress Phytotherapy 3: 175-8. (in Polish)

[49] Kalisz, O., Wolski, T., Gerkowicz, M., and Morawski, M. 2007. "Reactive Oxygen Species (ROS) and Their Role in the Pathogenesis of Certain Diseases." Annales Universitatis Mariae Curie-Skłodowska Lublin-Polonia 62 (1): 87-99.

[50] Chan, E. W., Lye, P. Y., and Wong, S. K. 2016. "Photochemistry, Pharmacology and Clinical Trials of Morus alba." Chinese Journal of Natural Medicines 14 (1): 17-30. 